\title{
Two Mannose-resistant Haemagglutinins on Enterotoxigenic Escherichia coli of Serotype O6:K15: H16 or H- Isolated from Travellers' and Infantile Diarrhoea
}

\author{
By CYRIL J. SMYTH† \\ Department of Bacteriology and Epizootiology, Swedish University of Agricultural Sciences, \\ College of Veterinary Medicine, Biomedical Centre, S-75I 23 Uppsala, Sweden
}

(Received 23 September 1981; revised 4 January 1982)

Enterotoxigenic Escherichia coli of serotype O6:K15:H16 or $\mathrm{H}-$ have been shown to cause MRHA of bovine erythrocytes (MRHA bov ), a characteristic associated with possession of socalled CFA (CFA/II) which facilitates adhesion to the intestinal mucosa. Using putative antiCFA/II antisera, raised to whole cell vaccines of $\mathrm{MRHA}_{\text {bov }}^{+}$prototype strains of different biotypes with subsequent absorption with their MRHA $_{\text {bov }}^{-}$variants, three immunologically distinct CS antigens were identified on enterotoxigenic strains of this serotype. CS1 antigen was found only on MRHA bov $^{+}$isolates of biotype A (rhamnose-negative). Specific anti-CSl antigen serum agglutinated rhamnose-negative strains, gave a single immunoprecipitate in double immunodiffusion against cell surface extracts of these bacteria, and only inhibited the MRHA activity of biotype A strains. The presence of CS1 serologically correlated with the presence of a $16.3 \mathrm{kDal}$ polypeptide band upon SDS-PAGE of extracts. CS2 antigen was identified on MRHA $_{\text {bov }}^{+}$strains of biotypes B, C and F (rhamnose-positive). Specific anti-CS2 antigen serum agglutinated only the latter strains, gave a single immunoprecipitate against cell surface extracts of only rhamnose fermenting strains, and only inhibited MRHA $_{\text {bov }}$ activity of strains of these biotypes. The presence of CS2 antigen serologically was associated with the presence of a $15 \cdot 3$ $\mathrm{kDal}$ polypeptide band in SDS-PAGE patterns of extracts. The CS3 antigen was identified by immunodiffusion tests with extracts of most $\mathrm{O} 6: \mathrm{K} 15: \mathrm{H} 16$ or $\mathrm{H}$-strains possessing CS1 or CS2 antigen, i.e. independently of biotype, and was associated with the presence of a $14.8 \mathrm{kDal}$ polypeptide band by SDS-PAGE. Anti-CS3 antigen antibodies did not agglutinate nor did they possess haemagglutination inhibition activity. CS3 antigen was also found on an enterotoxigenic isolate series of serotype $\mathrm{O} 8: \mathrm{K} 40: \mathrm{H} 9$, which was $\mathrm{MRHA}_{\overline{\mathrm{bov}}}^{-}$and lacked the CS1 and CS2 antigens. A number of CS2-only O-serogroup 6 strains were identified. Expression of MRHA bov activity and the production of CS1, CS2 and CS3 antigens were phenotypically suppressed by growth at $18^{\circ} \mathrm{C}$. Loss of ST and also, in most instances, of LT production accompanied loss of MRHA $_{\text {bov }}$ activity and loss of production of the CS1, CS2 and CS3 antigens. Thus, the findings demonstrate the presence of two serologically distinct, biotype-associated haemagglutinins with different molecular weight properties on $\mathrm{MRHA}_{\text {bov }}^{+}$enterotoxigenic $E$. coli of serotype $\mathrm{O} 6: \mathrm{K} 15: \mathrm{H} 16$ or $\mathrm{H}-$ of human origin and of a third non-haemagglutinating surface-associated antigen common to most strains which may also facilitate adhesion.

† Present address: Department of Microbiology, Moyne Institute, Trinity College, Dublin 2, Eire.

Abbreviations: CFA, colonization factor antigen; CS, coli surface-associated; HD, haemagglutinating dose; HI, haemagglutination inhibition; LT, heat-labile enterotoxin; MRHA, mannose-resistant haemagglutination; MSHA, mannose-sensitive haemagglutination; PBS, phosphate buffered saline; ST, heat-stable enterotoxin; TSB, trypticase soy broth. 


\section{INTRODUCTION}

In recent years, considerable attention has been devoted to mechanisms of adherence of enterotoxigenic Escherichia coli of human origin to human intestinal epithelial cells (Evans et al., 1975; Brinton, 1978; Evans \& Evans, 1978; Thorne et al., 1979; Deneke et al., 1980, 1981; Wadström et al., 1980). The MRHA property for certain erythrocyte species has been particularly useful in screening enterotoxigenic $E$. coli of human origin for adherence properties of potential significance in intestinal colonization (Ørskov \& Ørskov, 1977; Evans et al., 1977; Evans \& Evans, 1978; Freer et al., 1978; Gross et al., 1978; Evans, D. J. et al., 1979; Cravioto et al., 1979b; Smyth et al., 1979; Deneke et al., 1981). This has led to the identification on enterotoxigenic $E$. coli of two serologically distinct types of haemagglutinating fimbriae, viz., CFA/I and CFA/II (Evans et al., 1975, 1978, 1979; Evans \& Evans, 1978). CFA/I causes MRHA of human, bovine and chicken erythrocytes and is found on enterotoxigenic $E$. coli of serogroups O15, O25, O63, O78, O128 and O153 (Ørskov \& Ørskov, 1977; Evans \& Evans, 1978; Gross et al., 1978; Cravioto et al., 1979 b; Evans et al., 1979; Smyth et al., 1979; Wadström et al., 1979; Bäck et al., 1980 b). CFA/II causes MRHA of bovine and chicken erythrocytes, but not of human erythrocytes and is associated with strains of serogroups 06 and O8, in particular, but also with serogroups O80 and O85 (Ørskov \& Ørskov, 1977; Evans \& Evans, 1978; Evans, D. J. et al., 1979; Smyth et al., 1979; Wadström et al., 1979).

The present investigation arose from an attempt to produce a specific CFA/II antiserum according to the procedure of Evans \& Evans (1978), as in a three-and-a-half year study of tourist diarrhoea among homecoming Swedish residents, enterotoxigenic E. coli of serogroups O6 and O8 accounted for approximately $35 \%$ of enterotoxigenic isolates (Bäck et al., 1980a). In contrast to the findings of Evans \& Evans (1978), not all enterotoxigenic isolates of the serotype O6:K15:H16 or H- (Ørskov \& Ørskov, 1977) which caused MRHA of bovine erythrocytes $\left(\mathrm{MRHA}_{\text {bov }}^{+}\right.$) [i.e. which were putative CFA/II+ strains (Evans \& Evans, 1978)] reacted with the supposed specific anti-CFA/II serum (Smyth, 1980).

Accordingly, the aims of the present study were (i) to determine whether antigenic differences existed within this serotype of $\mathrm{MRHA}_{\text {bov }}^{+}$enterotoxigenic $E$. coli, (ii) to determine the basis for any such antigenic differences detected, (iii) to determine the spectrum of erythrocyte species agglutinated in a mannose-resistant manner by such strains and (iv) to determine whether biological and antigenic differences correlated with the different biotypes within this $O: K: H$ group of enterotoxigenic E. coli (Scotland et al., 1977). Two serologically distinct, surface associated haemagglutinins mediating $\mathrm{MRHA}_{\text {bov }}$ were found, the presence of which correlated with the rhamnose fermentation phenotype of the strains. In addition, a third surface-associated antigen was present which was common to most $\mathrm{MRHA}_{\mathrm{bov}}^{+}$enterotoxigenic $E$. coli of serotype $\mathrm{O} 6: \mathrm{K} 15: \mathrm{H} 16$ or $\mathrm{H}-$.

\section{METHODS}

Chemicals. LE agarose was obtained from Marine Colloids, Rockland, Me., U.S.A.; bovine serum albumin fraction V, mucic acid, and phenylmethylsulphonyl fluoride from Sigma; adonitol, dulcitol, raffinose, rhamnose and sorbose from both Merck and Fluka, Buchs, Switzerland; D-mannose from Merck; Dorset egg medium without crystal violet from Oxoid; TSB from BBL; all other chemicals were of analytical grade or best grade commercially available.

Bacteria. Pertinent characteristics and sources of the Escherichia coli strains used in this study are given in Table 1. Strains were preserved in TSB containing $15 \%(\mathrm{w} / \mathrm{v})$ glycerol at $-70^{\circ} \mathrm{C}$ and Dorset egg medium at $4{ }^{\circ} \mathrm{C}$.

Biotyping. The scheme developed by Scotland et al. (1977) was used. Carbohydrate breakdown tests on adonitol, dulcitol, raffinose, rhamnose and sorbose were performed in heart infusion broth containing $1 \%(w / v)$ of the saccharide with bromocresol purple as indicator. The mucate test was prepared according to Edwards \& Ewing (1972) with bromothymol blue as indicator.

Serotyping. $\mathrm{O}$ and $\mathrm{K}$ antigen determinations of strains supplied by E. Bäck and of Ethiopian isolates (Table 1) had been previously performed by B. Kaijser, Department of Clinical Bacteriology, University of Göteborg, Göteborg, Sweden. Strains C922a, B303dEt and B34212j were O : K : H serotyped by F. \& I. Ørskov, Collaborative Centre for Reference and Research on Escherichia and Klebsiella, Statens Seruminstitut, Copenhagen, Denmark. The serotypes of strains from M. Gurwith (Table 1) were accepted as supplied. $\mathrm{H}$ antigen determinations were performed by agglutination using an anti-H16 antiserum obtained by absorption of a polyvalent $\mathrm{O} 6: \mathrm{K} 15: \mathrm{H} 16$ 
Table 1. Characteristics of Escherichia coli strains

Strain/Year of isolation*

Serotype

Enterotoxin

$\left[\begin{array}{l}\mathrm{C} 921 \mathrm{a}, \mathrm{b}, \mathrm{d} / 77 \\ \mathrm{C} 921 \mathrm{f} / 77\end{array}\right.$
$\left[\begin{array}{l}\mathrm{C} 922 \mathrm{a}, \mathrm{b}, \mathrm{e}, \mathrm{f} / 77 \\ \mathrm{C} 922 \mathrm{c} / 77\end{array}\right.$

O6:K15:H16

O6:K13:H+

$\mathrm{O} 6: \mathrm{K} 15: \mathrm{H} 16$

O6:K $15: H 16$

C9la,b,c,d,e,f/78

$\mathrm{C} 407 \mathrm{a} / 78$

$\mathrm{O} 6: \mathrm{K} 15: \mathrm{H} 16$

$\mathrm{O} 6: \mathrm{K} 15: \mathrm{H} 16$

$\mathrm{C} 470 \mathrm{e} / 78$

$\mathrm{O} 6: \mathrm{K} 15: \mathrm{H}-$

C666c/78

O6:K $15: H 16$

$\mathrm{C} 728 \mathrm{~b} / 78$

O6 :K 15:H16

C735c/78

O6:K $15: H 16$

C806c/78

O6:K15:H16

C846e/78

E90a/79

E583a/79

E596a/79

$\mathrm{E} 628 \mathrm{~b} / 79$

E661a/79

B303dEt/77

$\left[\begin{array}{l}34318 \mathrm{a}, \mathrm{c}, \mathrm{e}, \mathrm{f} / 78 \\ 3699 / 78\end{array}\right.$
$\left[\begin{array}{l}34334 \mathrm{f} / 78 \\ \mathrm{E} 3772 / 78 \\ \mathrm{E} 3773 / 78\end{array}\right.$

$34413 \mathrm{~b} / 78$

$4071 / 78$

342(E4904)/76|!

344(E4833)/76 ||

O6 :H16

B34212b, c, h,j/78

H10407

H10407-P

NCTC 8623

$\mathrm{O} 8: \mathrm{K} 40: \mathrm{H} 9$

078:H11:CFA/I ${ }^{+}$

$\begin{array}{llll}\mathbf{L T}^{+} \mathrm{ST}^{+} & + & \text {TA } & \text { Spain } \\ \mathrm{LT}^{+} \mathrm{ST}^{-} & - & \text {TA } & \text { Spain } \\ \mathrm{LT}^{+} \mathrm{ST}^{+} & + & \text {TA } & \text { Spain } \\ \mathrm{LT}^{+} \mathrm{ST}^{-} & - & \text {TA } & \text { Spain } \\ \mathrm{LT}^{+} \mathrm{ST}^{+} & + & \text {TA } & \text { France } \\ \mathrm{LT}^{+} \mathrm{ST}^{+} & + & \text {TA } & \text { Spain } \\ \mathrm{LT}^{+} \mathrm{ST}^{+} & + & \text {TC } & \text { Tunisia }\end{array}$

$\mathrm{LT}^{+} \mathrm{ST}^{+}$

$\mathrm{LT}^{+} \mathrm{ST}^{+}$

$\mathrm{LT}^{+} \mathrm{ST}^{+}$

$\mathrm{LT}^{+} \mathrm{ST}^{+}$

$\mathrm{LT}^{+} \mathrm{ST}^{+}$

$\mathrm{LT}^{+} \mathrm{ST}^{+}$

$\mathrm{LT}^{+} \mathrm{ST}^{+}$

$\mathrm{LT}^{+} \mathrm{ST}^{+}$

$\mathrm{LT}^{+} \mathrm{ST}^{+}$

$\mathrm{LT}^{+} \mathrm{ST}^{+}$

O6 :K15:H16

$\mathrm{O} 6: \mathrm{K} 15: \mathrm{H}-$

O6:K15:H16

$\mathrm{LT}^{+} \mathrm{ST}$

$\mathrm{LT}^{+} \mathrm{ST}^{+}$

$\mathrm{LT}^{+} \mathrm{ST}^{+}$

$\mathrm{LT}^{+} \mathrm{ST}^{+}$

$\mathrm{LT}^{+} \mathrm{ST}^{+}$

$\mathrm{LT}^{+} \mathrm{ST}^{+}$

$\mathrm{LT}^{+} \mathrm{ST}^{+}$

O78:H11:CFA/I-

$\mathrm{LT}^{+} \mathrm{ST}^{-}$

O125:K $70: H 19$

$\mathrm{LT}^{-} \mathrm{ST}^{-}$

$\mathrm{O} 6: \mathrm{K} 2 \mathrm{a} 2 \mathrm{c}: \mathrm{H} 1$

$\mathrm{LT}^{-} \mathrm{ST}$

$\mathrm{LT}^{+} \mathrm{ST}^{+}$

$\mathrm{O} 6: \mathrm{K} 15: \mathrm{H} 16$

C922a-19

C922b-9,-13,-20

$342-15,-17$

E583a-7

or $\mathrm{H}^{-}$or

O6:H16
TA Greece

TA The Gambia

TA Tunisia

TA France

TA Sri Lanka

TA India

TA Cuba

TA Peru

TC Mozambique

TA USSR

I Ethiopia

I Ethiopia

I Ethiopia

I Ethiopia

I Ethiopia

SIDS Canada

SIDS Canada

I Ethiopia

A Bangladesh

LS

G England

UTI Sweden

LS
Source§ Reference

EB $]$ Bäck et al.

EB $(1980 a)$

EB Smyth et al.

EB (1979)

EB Bäck et al. (1980a)

EB Bäck et al (1980a)

EB Bäck et al. (1980a)

EB Bäck et al. (1980a)

EB Bäck et al. (1980a)

EB Bäck et al. (1980a)

EB Bäck et al. (1980a)

EB Bäck et al. (1980a)

EB Bäck et al. (1980a)

EB Bäck et al. (1980a)

EB Bäck et al. (1980a)

EB Bäck et al. (1980a) $\left\{\begin{array}{c}\text { Bäck et al. } \\ (1980 b)\end{array}\right.$

Smyth et al (1979)

GS Stintzing et al. (1982)

GS Stintzing et al. (1982)

GS Stintzing et al. (1982)

GS Stintzing et al. (1982)

MG Brunton et al. (1980)

MG Brunton et al. (1980)

GS Stintzing et al. (1981)

DE Evans et al. (1975)

DE Evans et al. (1975)

JHF Sweeney \& Freer (1979)

RM

CJS $\left\{\begin{array}{l}\text { Wadström et al. } \\ (1979) \\ \text { Wadström et al. } \\ (1980 a, b)\end{array}\right.$

(continued) 
Table 1 (continued)

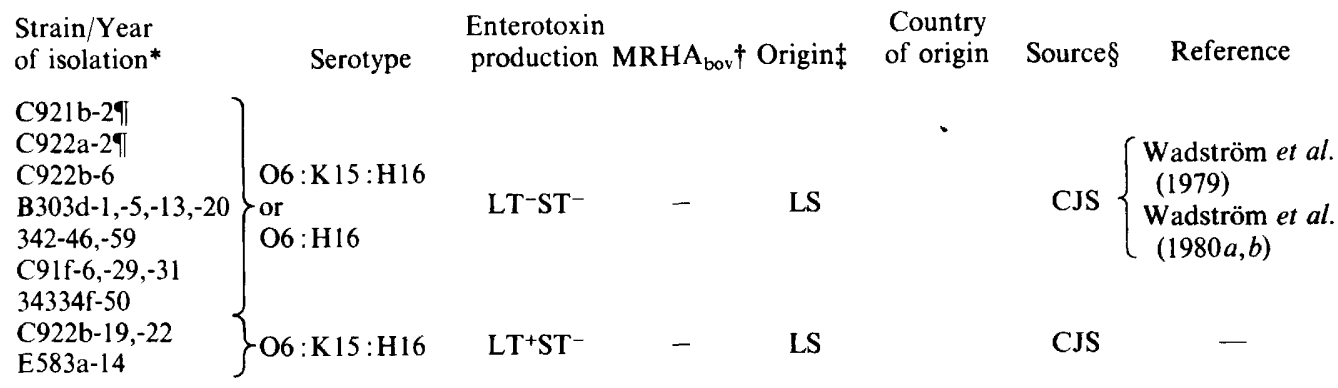

* Designations a, b, c etc. indicate single colony isolates from the same patient upon primary culture of stool specimens on Endo agar; square bracketed strains indicate strains from same patient; numbers after strain designation, e.g. C922a-1, indicate single colony substrains from parent strain elsewhere in Table.

$\dagger$ Mannose-resistant haemagglutination of bovine erythrocytes; reactions determined by author and cited by Bäck et al. $(1980 a, b)$, Stintzing et al. $(1981,1982)$, Smyth et al. (1979) and Wadström et al. (1979).

‡ TA, travellers' diarrhoea, adult; TC, travellers' diarrhoea, child; I, infantile diarrhoea; G, gastroenteritis; A, adult cholera-like diarrhoea; SIDS, sudden infant death syndrome; LS, laboratory substrain from single colony; UTI, urinary tract infection.

$\S$ E.B, Erik Bäck, Regionsjukhuset, Örebro, Sweden; RM, Roland Möllby, National Bacteriological Laboratory, Stockholm, Sweden; GS, Gudmund Stintzing, National Bacteriological Laboratory, Stockholm, Sweden; MG, Marc Gurwith, Division of Infectious Diseases, Wadsworth Veterans' Hospital, Los Angeles, Calif., U.S.A.; JHF, John H. Freer, Department of Microbiology, University of Glasgow, Glasgow, Scotland; DE, Dolores and Doyle Evans, University of Texas Medical School at Houston, Houston, Tex., U.S.A.

I| Strain designations in parentheses are the Colindale numbers assigned to the strains originally received from M. Gurwith (Scotland et al., 1977).

I Only strains indicated used in literature cited.

antiserum, kindly supplied by F. \& I. Ørskov, with live and autoclaved cells of $\mathrm{MRHA}_{\mathrm{bov}}^{+}$enterotoxigenic $E$. coli of serotype $\mathrm{O} 6: \mathrm{K} 15: \mathrm{H}-$.

Enterotoxin tests. The enterotoxigenic strains in Table 1 had been shown to produce $\mathrm{LT}$ using the $\mathrm{Y} 1$ adrenal cell test (Söderlind \& Möllby, 1978; Bäck et al., 1979, 1980a, b; Stintzing et al., 1981, 1982; Brunton et al., 1980) or using the Chinese hamster ovary cell test (Guerrant $e t$ al., 1974). Production of ST was monitored by the infant mouse test according to Giannella (1976), with an intestinal weight to remaining carcass weight ratio of $\geqslant 0.090$ being considered as positive (Olsson \& Söderlind, 1980). Determination of enterotoxin production by MRHA $_{\text {bov }}^{+}$ substrains and $\mathrm{MRHA}_{\text {bov }}^{-}$variants (Table 1 ) and repetition of tests on particular strains was performed by these procedures. The author thanks E. Olsson, Department of Bacteriology and Epizootiology, Biomedical Centre, Uppsala and G. Sigstam, Department of Bacteriology, Karolinska Institute, Stockholm, Sweden for performing these ST and LT tests, respectively.

Haemagglutination. Strains were routinely grown on modified CFA agar medium (Evans et al., 1977) at $37^{\circ} \mathrm{C}$ for $18 \mathrm{~h}$. Bacteria were suspended directly from CFA agar in $0.15 \mathrm{M}-\mathrm{NaCl}$ using cotton swabs to obtain homogeneous suspensions. The growth from half of a CFA agar plate $(90 \mathrm{~mm})$ when suspended in $1 \mathrm{ml} \mathrm{NaCl}$ yielded about $10^{10}$ bacteria $\mathrm{ml}^{-1}$. All erythrocytes were washed three times with $0 \cdot 15 \mathrm{M}-\mathrm{NaCl}$ and suspended to $3 \%(\mathrm{v} / \mathrm{v})$ with respect to initial blood volume. The following erythrocyte species were tested: cat, chicken, cow, dog, guinea-pig, hen, horse, human Group A, mouse, pig, rabbit and sheep.

Haemagglutination tests were performed by mixing one drop each of bacterial suspension, erythrocyte suspension and $0.1 \mathrm{M}-\mathrm{D}-\mathrm{mannose}$ in $0.15 \mathrm{M}-\mathrm{NaCl}$ or $0.15 \mathrm{M}-\mathrm{NaCl}$. Glass cavity slides or glass tiles with oval or round depressions were rocked gently with a swirling action at $20^{\circ} \mathrm{C}-22^{\circ} \mathrm{C}$. Strong agglutination reactions occurred within $30 \mathrm{~s}$. Mixtures were subsequently incubated at $4^{\circ} \mathrm{C}$ for up to $20 \mathrm{~min}$ before another reading was made.

In addition, strains were sequentially subcultured three times at 48 to $72 \mathrm{~h}$ intervals in $10 \mathrm{ml}$ TSB in test tubes with incubation without shaking at $37^{\circ} \mathrm{C}$ (Nowotarska \& Mulczyk, 1977; Duguid \& Old, 1980). Cells were sedimented by centrifugation $\left(3250 \mathrm{~g}, 10 \mathrm{~min}, 20^{\circ} \mathrm{C}\right)$ and suspended gently in $1 \mathrm{ml}$ of $0.15 \mathrm{M}-\mathrm{NaCl}$ for haemagglutination tests in the presence and absence of $\mathrm{D}$-mannose.

Titrations of haemagglutinating activity were performed using doubling dilutions of bacterial suspensions in 50 $\mu \mathrm{l}$ of $0.15 \mathrm{M}-\mathrm{NaCl}$ to which $50 \mu \mathrm{l}$ each of $0.1 \mathrm{M}-\mathrm{D}$-mannose and erythrocyte suspension was added. One HD of bacteria was defined as the amount giving complete or virtually complete haemagglutination of bovine erythrocytes in $5 \mathrm{~min}$ at $20^{\circ} \mathrm{C}$. 
Selection of MRHA $A_{\text {bov }}^{-}$variants. This has been detailed previously (Wadström et al., 1979). Briefly, colonies were subcultured from modified CFA agar plates to fresh CFA agar plates (four per plate), incubated at $37^{\circ} \mathrm{C}$ for $18 \mathrm{~h}$, and bacterial suspensions tested for the MRHA $_{\text {bov }}$ property. To select variants in Table 1, any number of colonies from 5 to 1000 had to be tested to find at least one $\mathrm{MRHA}_{\overline{\mathrm{bov}}}$ variant for any particular strain. $\mathrm{MRHA}_{\overline{\mathrm{bov}}}$ variants were checked for biotype and O6:H16 serotype.

Preparation of antisera against cell surface-associated antigens of $M R H A_{b o v}^{+}$strains. The procedure and schedule of Evans et al. (1975) for production of anti-CFA/I and anti-CFA/II sera (Evans \& Evans, 1978) was followed using formalin-treated vaccines of strains C922a-1, B303dEt, C9If and 34334f (Table 1). Two rabbits each were used with the first two named strains and one rabbit each with the latter two strains. In each instance, an antiserum pool was absorbed with live and autoclaved cells of a $\mathrm{MRHA}_{\mathrm{bov}}^{-}$variant or substrain of the same parent culture, viz., strains C922a-2, B303d-5, C91f-6 and 34334f-50, respectively (Table 1).

The immunoglobulin fractions were partially purified from the absorbed sera by ammonium sulphate precipitation, followed by sequential dialysis against acetate buffer and distilled water according to Harboe \& Ingild (1973). Precipitate was removed by centrifugation before final dialysis against $0 \cdot 1 \mathrm{M}-\mathrm{NaCl}$ containing 15 $\mathrm{mM}-\mathrm{NaN}_{3}$ as preservative. Immunoglobulins were concentrated threefold with respect to serum volume (used undiluted in immunodiffusion tests) and stored at $4{ }^{\circ} \mathrm{C}$. Antisera termed anti-C922a-1, anti-B303dEt, anti-C91f and anti-34334f refer to the partially purified immunoglobulin preparations from absorbed sera.

Anti-CFA/I serum was prepared in an identical manner using strain $\mathrm{H}-10407$ as the vaccine and $\mathrm{H}-10407-\mathrm{P}$ for absorption (Evans et al., 1975; Smyth et al., 1979; Wadström et al., 1979). Specific antisera against CS antigens designated CS1, CS2, and CS3 (see Results) were obtained by cross-absorption of sera. Anti-CS3 serum was obtained by absorption of anti-34334f serum with strain C91f, and anti-CS1 and anti-CS2 sera, by absorption of anti-C922a-l and anti-34334f sera, respectively, with strain B34212j. In addition, anti-C91f serum served as an anti-CS2 serum by its nature (see Fig. 1 and Results).

Agglutination. Bacterial suspensions (about $10^{9}$ bacteria ml $^{-1}$ of $0.15 \mathrm{M}-\mathrm{NaCl}$ ) prepared from overnight growth on CFA agar plates were tested by slide agglutination procedures using saline or prevaccination rabbit serum for controls.

Agglutination titres of antisera were determined by serial doubling dilutions of antisera ( $50 \mu \mathrm{l})$ in PBS containing $0.02 \%(\mathrm{w} / \mathrm{v})$ bovine serum albumin (Evans \& Evans, 1978) using 96-well, U-shaped microtitre plates (Linbro Chemical Co., New Haven, Conn., U.S.A.). Suspensions of CFA agar-grown bacteria were adjusted to an $A_{600}=2.0 \mathrm{in} \mathrm{a} 10 \mathrm{~mm}$ lightpath (Evans \& Evans, 1978). Portions $(50 \mu \mathrm{l}$ ) of the bacterial suspensions were added to the antiserum-containing wells, the plates sealed and the mixtures incubated at $37^{\circ} \mathrm{C}$ for $2 \mathrm{~h}$. The agglutinating titre was read after incubation overnight at $4{ }^{\circ} \mathrm{C}$. The titre was defined as the dilution of antiserum giving $50-100 \%$ agglutination of the bacteria. Titres of immunoglobulin preparations from absorbed antisera were all expressed relative to serum volume.

Haemagglutination inhibition. Antisera $(25 \mu \mathrm{l})$ were diluted in doubling dilution series in PBS with $0.02 \%$ bovine serum albumin in wells of glass tiles. To each well, $25 \mu \mathrm{l}$ of bacterial suspension was added. The bacterial suspensions had been adjusted to contain 8 to $16 \mathrm{HD}$ of bacteria per sample, i.e. the bacterial suspensions had different cell densities ( $A_{600}$ values). In HI tests most authors use $4 \mathrm{HD}$; the higher dose was chosen herein as it gave clearcut haemagglutination reactions with different strains, especially those fermenting rhamnose (see Results). After incubation of the mixtures for $1 \mathrm{~h}$ at $37^{\circ} \mathrm{C}$, they were allowed to cool for $10 \mathrm{~min}$ to room temperature $\left(18{ }^{\circ} \mathrm{C}\right.$ to $20^{\circ} \mathrm{C}$ ). To each well $25 \mu \mathrm{l} 0 \cdot 1 \mathrm{M}$-D-mannose and $3 \%$ bovine erythrocyte suspension was added. The dilution of antiserum showing inhibition of haemagglutination after incubation at $20^{\circ} \mathrm{C}$ for $5 \mathrm{~min}$ followed by $20 \mathrm{~min}$ at $4{ }^{\circ} \mathrm{C}$ was taken as the $\mathrm{HI}$ titre.

Preparation of extracts containing cell surface-associated antigens. A method similar to that first used to isolate K88 antigen (Stirm et al., 1967) and which has sutsequently been used in the isolation of K99 antigen (Morris et al., 1977), CFA/I (Freer et al., 1978) and F7 antigen (Ørskov et al., 1980) was employed. Bacteria were harvested from five CFA agar plates in $2 \mathrm{ml} 0.15 \mathrm{M}-\mathrm{NaCl}, \mathrm{pH} 7.0$ using cotton-tipped swabs. The suspensions were heated at $60^{\circ} \mathrm{C}$ for $20 \mathrm{~min}$ and the bacteria sedimented by centrifugation $\left(27000 \mathrm{~g}, 10 \mathrm{~min}, 4^{\circ} \mathrm{C}\right)$. Supernatant fractions were filtered through membrane filters $(0.65 \mu \mathrm{m}$ pore diam., Millipore). Extracts were stored as 50 or $100 \mu \mathrm{l}$ portions at $-70^{\circ} \mathrm{C}$ until used in immunodiffusion or SDS-PAGE studies (see below). After thawing once, any remaining extract was discarded. In certain control experiments (see Results), extracts were prepared by shearing bacteria in a homogenizer $\left(6 \times 1 \mathrm{~min}, 20000 \mathrm{rev}\right.$. $\mathrm{min}^{-1}$ on ice) with subsequent processing as heat-released extracts. To control for proteolysis, heat extracts were prepared from saline suspensions of bacteria in the presence and absence of $1 \mathrm{mM}$-phenylmethylsulphonyl fluoride using the same batches of cells.

Double immunodiffusion. Tests were performed in $1 \%(\mathrm{w} / \mathrm{v})$ agarose gels in sodium barbital-barbital buffer containing $\mathrm{NaN}_{3}(I=0.02, \mathrm{pH} 8.6)$ (Weeke, 1973). Glass slides $(50 \times 50 \mathrm{~mm})$ were lightly coated with agarose. Gels were cast on a levelling table to give a volume-to-surface ratio of $0.14 \mathrm{ml}$ agarose $\mathrm{cm}^{-2}$. Wells of $2.5 \mathrm{~mm}$ diam. were routinely used with an intercentre distance of $7.5 \mathrm{~mm}$. In the absorption experiments (see Results), 3 or $4 \mathrm{~mm}$ diam. wells were used for antiserum or antigen or both. Wells were charged with $10 \mu \mathrm{l}(20 \mu \mathrm{l}$ with larger wells) of 
antigen preparation or antiserum and the slides incubated at $20^{\circ} \mathrm{C}$ to $22^{\circ} \mathrm{C}$ for $48 \mathrm{~h}$. Drawings were made of immunoprecipitates before gels were washed, dried, and stained with Coomassie brilliant blue according to Weeke (1973). Immunoprecipitates and reactions of identity or non-identity which were not visible in the unstained gels were added to the original diagrams in a distinguishing colour.

Preparation of immunoprecipitates for immunization. Heat-released extracts of strain C922a-1 were diffused against anti-C922a-I serum to obtain CS1 immunoprecipitates, and heat extracts of strain B34212j, against antiB303dEt serum to obtain CS3 immunoprecipitates. Gels were washed with $0 \cdot 1 \mathrm{M}-\mathrm{NaCl}$ and pressed between washes according to Weeke (1973). Immunoprecipitates were excised after washing for $48 \mathrm{~h}$ using a $1.5 \mathrm{~mm}$ diam. gel punch. Gel discs from two 9-well immunoplates were pooled for each immunogen into $2.0 \mathrm{ml}$ of $0.15 \mathrm{M}-\mathrm{NaCl}$ and the mixtures homogenized using glass tissue grinders until the agarose was visibly dispersed. Immunogens were stored at $-20^{\circ} \mathrm{C}$ until used as small samples. Preparations were only used when subsequent staining of immunoplates provided evidence of precision in excision. Rabbits received the immunogens in Freund's incomplete adjuvant as five equal doses: day 0 , intracutaneously at multiple sites on the back; days $7,14,21$ and 40 , intramuscularly.

Antisera were absorbed with strain C922a-2 (live and autoclaved cells) and with strain B34212j (autoclaved cells only), respectively. The specificities of these antisera were checked by immunodiffusion tests and agglutination tests before use. The anti-CS1 and anti-CS3 sera obtained in this manner behaved identically to those obtained by cross-absorption (see above).

$S D S-P A G E$. For SDS-PAGE, samples adjusted to a concentration of $0.5 \mathrm{mg}$ protein $\mathrm{ml}^{-1}$ were suspended in $1 \%(\mathrm{w} / \mathrm{v})$ SDS, $2 \%(\mathrm{w} / \mathrm{v})$ mercaptoethanol, $20 \mathrm{mM}$-Tris, $8 \mathrm{mM}$-sodium phosphate and $5 \%(\mathrm{w} / \mathrm{v})$ glycerol, $\mathrm{pH} 7 \cdot 8$. Preparations were boiled for $5 \mathrm{~min}$ immediately prior to application to the polyacrylamide gel slabs.

The discontinuous SDS gel system was essentially that of Laemmli (1971) with slight modifications. The separation gel $(0.5 \mathrm{~mm}$ thick, $0.1 \% \mathrm{SDS}, 15 \%$, w/v polyacrylamide) had a $\mathrm{pH}$ of 8.9 . The stacking gel (pH 7.8) comprised $5 \%(\mathrm{w} / \mathrm{v})$ acrylamide, $62.5 \mathrm{mM}$-Tris, $56 \mathrm{mM}$-sodium phosphate and $0.1 \%(\mathrm{w} / \mathrm{v}) \mathrm{SDS}$. The electrode buffer contained $29 \mathrm{mM}$-Tris, $220 \mathrm{~mm}$-glycine and 0.1\% SDS, pH 8.6. After electrophoresis, the gels were stained with Coomassie brilliant blue according to Fairbanks et al. (1971), mounted on filter paper, and dried under vacuum. Molecular weight standards were bovine serum albumin (68 kDal), ovalbumin (45 $\mathrm{kDal})$, carbonic anhydrase $(29 \mathrm{kDal})$, soybean trypsin inhibitor $(21 \mathrm{kDal})$, myoglobin $(17.8 \mathrm{kDal})$ and cytochrome $c(12.4 \mathrm{kDal})$.

\section{RESULTS}

\section{Initial observations}

Anti-C922a-1 serum was initially tested in the autumn of 1978 as a putative anti-CFA/II serum against the isolate series C921a, b, d, C922a, b, f, C91a-f and strain B303dEt (Table 1), and seven Ethiopian isolates and one East German strain of enterotoxigenic $E$. coli not included in the present study but also of serotype $\mathrm{O} 6: \mathrm{K} 15: \mathrm{H} 16$ or $\mathrm{O} 6: \mathrm{K} 15$, which together comprised the $21 \mathrm{MRHA}_{\text {bov }}^{+}$strains from 10 patients included in the study of Smyth et al. (1979). All except strains B303dEt and C91a-f were agglutinated by anti-922a-1 serum. Using the biotyping scheme of Scotland et al. (1977), the agglutinable strains were of biotype A, whereas strains B303dEt and C91 a-f were of biotypes B and C, respectively. Accordingly, strains B303dEt, C91f and 34334f, a non-agglutinable $\mathrm{MRHA}_{\text {bov }}^{+}$strain of biotype $\mathrm{F}$, were chosen as representative MRHA $_{\text {bov }}^{+}$strains of biotypes other than biotype A from which to select MRHA $_{\text {bov }}^{-}$variants and were used for production and absorption of antisera, respectively.

\section{Agglutination and double immunodiffusion tests with prototype $M R H A_{b o v}^{+}$strains of biotypes $A, B$, $C$ and $F$ and their $M R H A_{b o v}^{-}$variants}

The absorbed antisera were titrated against the homologous and heterologous MRHA bov $^{+}$ strains and their MRHA $_{\overline{b o v}}$ variants (Table 2). The anti-C922a-1 serum agglutinated only the homologous strain. The anti-B303dEt, anti-C91f and anti-34334f sera did not agglutinate strain C922a-1, but each gave equivalent titres against the homologous and the other two heterologous MRHA $_{\text {bov }}^{+}$strains. The MRHA $_{\text {bov }}^{-}$variants of these prototype strains were not agglutinated to any significant extent by any of these four antisera. Heated bacterial suspensions $\left(121^{\circ} \mathrm{C}, 2 \mathrm{~h}\right)$ were not agglutinated by any of the antisera. Neither was any of these strains agglutinated by the anti-CFA/I serum.

Immunodiffusion tests with heat-released extracts gave the homologous and heterologous reactions shown in Fig. 1. Three distinct immunoprecipitates were recognized. The antigens 
Table 2. Agglutination titres of absorbed antisera against prototype $M R H A_{\mathrm{bov}}^{+}$strains of enterotoxigenic Escherichia coli of $O$-serogroup 6 and their $M R H A_{\mathrm{bov}}^{-}$variants

$\begin{array}{lcccccc}\text { Strain } & \text { MRHA }_{\text {bov }} & \text { Biotype* } & \text { C922a-1 } & \text { B303dEt } & \text { C91f } & 34334 f \\ \text { C922a-1 } & + & \text { A } & 1: 32 & <1: 2 & <1: 2 & <1: 2 \\ \text { C922a-2 } & \text { - } & \text { A } & <1: 2 & 1: 2 & <1: 2 & <1: 2 \\ \text { B303dEt } & + & \text { B } & <1: 2 & 1: 128 & 1: 128 & 1: 1024 \\ \text { B303d-5 } & - & \text { B } & <1: 2 & 1: 2 & <1: 2 & <1: 2 \\ \text { C91f } & + & \text { C } & <1: 2 & 1: 128 & 1: 128 & 1: 1024 \\ \text { C91f-6 } & - & \text { C } & <1: 2 & 1: 2 & <1: 2 & <1: 2 \\ \text { 34334f } & + & \text { F } & <1: 2 & 1: 64 & 1: 128 & 1: 1024 \\ \text { 34334f-50 } & - & \text { F } & <1: 2 & <1: 2 & <1: 2 & <1: 2\end{array}$

* According to Scotland et al. (1977); biotype A is rhamnose-negative and biotypes B, C and F are rhamnosepositive

giving rise to these immunoprecipitates were designated CS antigens, viz., CS1, CS2 and CS3 (Fig. 1). CS1 antigen was specific to strain C922a-1 and precipitins to it were only found in the homologous antiserum. CS2 antigen was detected in extracts of strains B303dEt, C91f and $34334 \mathrm{f}$ using any of the antisera to these three strains, but not in extracts of strain C922a-1. Antigen CS3 was present in extracts of strains C922a-1, B303dEt and 34334f, despite the lack of cross-agglutination of strain C922a-1 with antisera to either of the other two strains and vice versa (Table 2). The precipitins against CS3 were of lower titre in the anti-C922a-1 serum than in the anti-B303dEt and anti-34334f sera (in Fig. 1 these antisera are used at equivalent concentration). Anti-C91f serum lacked precipitins for the CS3 antigen and extracts of strain C91f were negative for antigen CS3. No immunoprecipitates were obtained between extracts of these four strains and anti-CFA/I serum. Extracts of the four MRHA $_{\text {bov }}^{-}$variants yielded no immunoprecipitates with any of these five antisera (Fig. 1). By appropriate immunodiffusion tests, CS1, CS2 and CS3 showed reactions of non-identity (see Fig. $1 b$ and $d$; other data not shown).

Extracts of the four prototype $\mathrm{MRHA}_{\mathrm{bov}}^{+}$strains prepared by shearing of cells but otherwise processed identically to heat-released extracts gave rise to immunoprecipitation patterns indistinguishable from those obtained in Fig. 1 and gave reactions of identity with the standard extracts. As several proteases and peptidases have been described to be membrane-associated in E. coli or to be present in the periplasm (e.g. Lazdunski et al., 1975; Paucaud et al., 1976), heatreleased extracts of strains were prepared in the presence of PMSF. These PMSF extracts of the prototype strains gave identical immunodiffusion patterns to those obtained with the standard heat-released extracts (Fig. 1). Suspensions of bacteria in saline containing PMSF retained the same agglutinability as those in saline alone (cf. Table 2).

In a previous study (Smyth et al., 1979), it had been shown that growth of MRHA bov enterotoxigenic $E$. coli of serotype $\mathrm{O6}: \mathrm{K} 15$ at $18^{\circ} \mathrm{C}$ on CFA agar suppressed expression of the MRHA $_{\text {bov }}$ characteristic. Suspensions of $18^{\circ} \mathrm{C}$-grown bacteria $(48 \mathrm{~h})$ of the prototype strains were MRHA $_{\overrightarrow{b o v}}$ and were not agglutinated by any of the four absorbed antisera. Heat-released extracts of these $18^{\circ} \mathrm{C}$-grown bacteria did not contain CS1, CS2 and CS3 antigens by double immunodiffusion tests. Upon subculture of the $18^{\circ} \mathrm{C}$-grown bacteria to fresh CFA agar plates and growth at $37^{\circ} \mathrm{C}$ for $18 \mathrm{~h}$, the three properties were regained.

\section{Cross-absorption studies}

Samples of anti-C922a-1 and anti-34334f sera were absorbed with strains C922b-13 (a single colony substrain identical in all respects to strain C922a-1) C91f and 34334f. Absorption of antiC922a-1 serum with strain C922b-13 abolished agglutinating activity towards the biotype $A$ strains C922a-1 and C922b-13, whereas absorption with strain C91f possessing only the CS2 antigen or with strain $34334 \mathrm{f}$ possessing both CS2 and CS3 antigens did not affect the agglutinating titre towards the biotype A strains. Conversely, absorption of anti-34334f with 

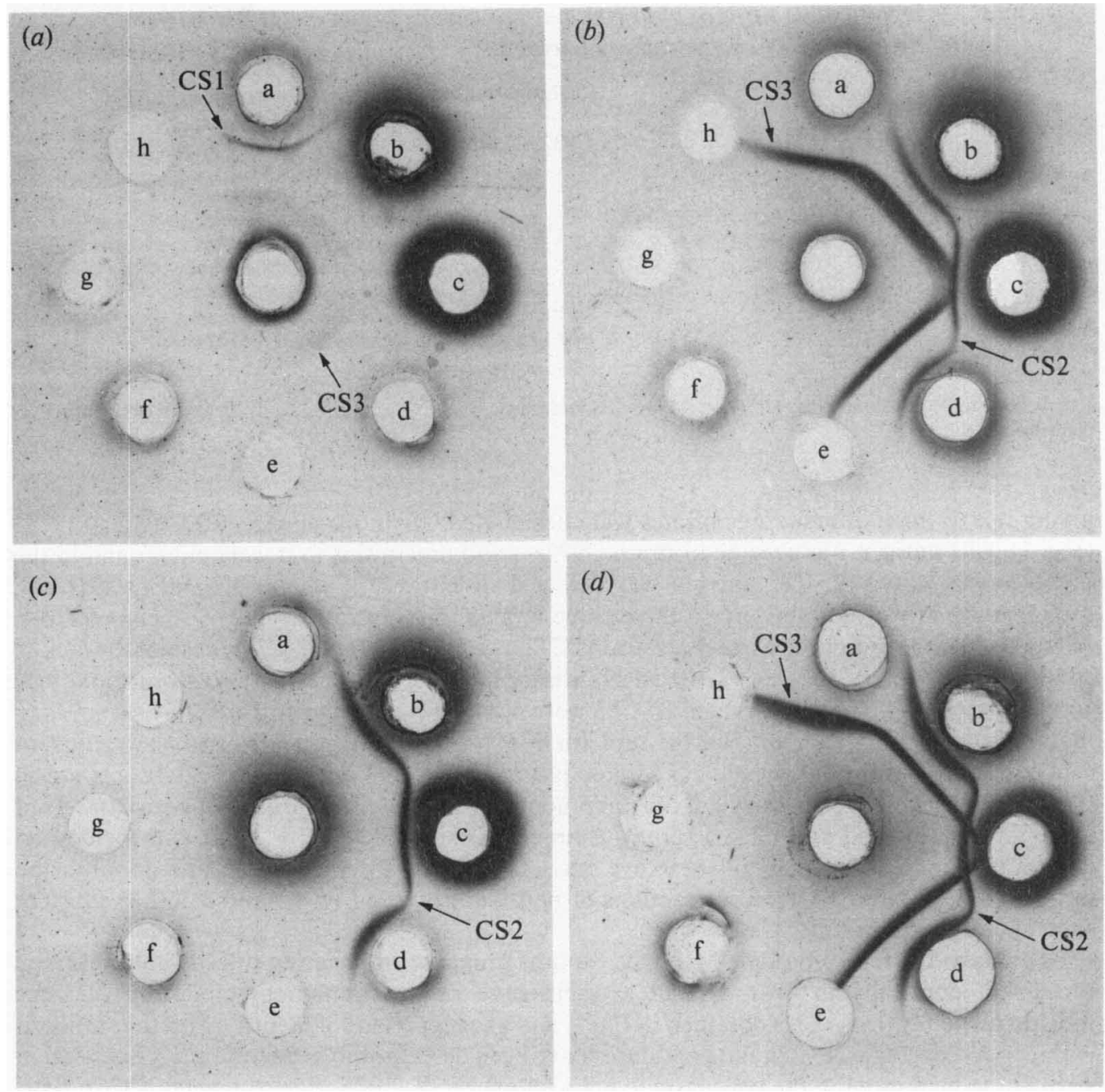

Fig. 1. Double immunodiffusion analysis of heat-released extracts $\left(60^{\circ} \mathrm{C}, 20 \mathrm{~min}\right)$ of prototype MRHA $_{\text {bov }}^{+}$enterotoxigenic $E$. coli of serotype $06: \mathrm{K} 15: \mathrm{H} 16$ or $\mathrm{H}-$ and of their MRHA ${ }_{\text {bov }}^{-}$variants. Peripheral wells of immunoplates $(a),(b),(c)$ and $(d)$ were loaded with heat-released extracts of strains C922a-1(a), B303dEt (b), C91f (c), 34334f (d), C922a-2 (e), B303d-5 (f), C91f-6 (g) and 34334f-50 (h), $10 \mu \mathrm{l}$ portions being used in each instance. Centre wells were charged with $10 \mu \mathrm{l}$ anti-C922a-1 (a), antiB303dEt $(b)$, anti-C91f $(c)$ and anti-34334f $(d)$ antisera. Immunoplates were stained with Coomassie brilliant blue after $48 \mathrm{~h}$ at $20^{\circ} \mathrm{C}$. Immunoprecipitates corresponding to CS antigens CS1, CS2 and CS3 are indicated.

strain C922b-13 possessing antigens CS1 and CS3 had no effect on its agglutinating titre towards strains C91f and 34334f, whereas absorption with either of the latter strains removed agglutinating antibodies for these strains.

Removal of precipitins towards CS1 and CS2 from anti-C922a-1 and anti-34334f sera, respectively, correlated with the loss of agglutinating antibodies. Anti-34334f serum absorbed with strain C91f, i.e. specific anti-CS3 serum, did not agglutinate any of these four test strains. The cross-absorptions with strains C922b-13 and $34334 \mathrm{f}$ removed anti-CS3 precipitins only.

Absorption of these two antisera with $E$. coli strain NCTC 8623, grown as unshaken TSB cultures to provide abundant type 1 fimbriae production (Nowotarska \& Mulczyk, 1977; Sweeney \& Freer, 1979), neither affected the agglutinating titre of these antisera nor removed 
precipitins for CS1, CS2 and CS3 antigens. Likewise, absorption of these two antisera with the prototype $\mathrm{CFA} / \mathrm{I}^{+}$strain $\mathrm{H}-10407$ removed neither agglutinins nor precipitins.

Isolate series $B 34212 b, c, h$ and $j / 78$

By a fortuitous accident, extracts of the $\mathrm{MRHA}_{\text {bov }}^{-}$enterotoxigenic $E$. coli strain $\mathrm{B} 34212 \mathrm{j}$ of serotype $08: \mathrm{K} 40: \mathrm{H} 9$ (Table 1), obtained by both shearing and heat-release, were examined in immunodiffusion tests against anti-C922a-1, anti-B303dEt, anti-C91f and anti-34334f sera. Although none of these sera agglutinated strain B34212j, an immunoprecipitate showing a reaction of identity with that of CS3 antigen was observed. Identical findings were obtained with the other substrains of the B34212 isolate series. Moreover, absorption of anti-C922a-1 and anti-34334f sera with strain B34212j absorbed out anti-CS3 antibodies resulting in specific antiCS1 and anti-CS2 sera, which retained the ability to agglutinate strain C922a-1 and strains B303dEt, C91f and 34334f, respectively. The anti-CS1 and anti-CS2 sera neither agglutinated the MRHA $_{\text {bov }}^{-}$variants of the prototype strains nor reacted with extracts of the MRHA $_{\text {bov }}^{-}$ variants by immunodiffusion.

\section{Haemagglutinin identity}

In order to determine the relationship between the antigens detected in immunodiffusion tests and the haemagglutinin(s) on the four prototype strains, antisera specific for CS1, CS2 and CS3 antigens were employed. Anti-CS1 and anti-CS3 sera were obtained by cross-absorption and by immunization with immunoprecipitates; one anti-CS2 serum was obtained by cross-absorption and the other was the anti-C91f serum (see above and Methods). The two anti-CS1 sera inhibited only the MRHA $_{\text {bov }}$ activity of the biotype A strain C922a-1. The two anti-CS2 sera caused inhibition only of the $\mathrm{MRHA}_{\mathrm{bov}}$ reactions of strains known to possess this antigen, i.e. strains B303dEt, C91f and 34334f. The two anti-CS3 sera lacked haemagglutination inhibition activity against all four prototype strains.

\section{SDS-PAGE of extracts of $M R H A_{\text {bov }}^{+}$prototype strains}

Examination of the heat-released extracts of the prototype strains by SDS-PAGE revealed the presence of three characteristic polypeptide bands which were absent from the profiles of their $\mathrm{MRHA}_{\text {bov }}^{-}$variants, as exemplified in Fig. 2. One band of $14.8 \mathrm{kDal}$ was common to strains C922a-1, B303dEt and 34334f, but lacking in the SDS-PAGE profile of strain C91f. The other two bands showed a biotype correlation, namely, that of $16.3 \mathrm{kDal}$ was only present in extracts of C922a-l, whereas that of $15 \cdot 3 \mathrm{kDal}$ was only present in the profiles of the prototype strains of biotypes B, C and F. The SDS-PAGE polypeptide band profiles of extracts obtained by shearing bacteria differed only in the intensity of bands other than those specific for MRHA bov $^{+}$ prototype strains. Extracts of isolates $\mathrm{B} 34212 \mathrm{~b}, \mathrm{c}, \mathrm{h}$ and $\mathrm{j}$ showed a strong polypeptide band corresponding to the $14.8 \mathrm{kDal}$ component of the serogroup O6 prototype strains (data not shown).

The polypeptide band patterns of heat-released extracts of the prototype $\mathrm{CFA} / \mathrm{I}^{+}$and $\mathrm{CFA} / \mathrm{I}^{-}$ strains of Evans et al. (1975) are representative of those obtained for each of seven other paired $\mathrm{CFA} / \mathrm{I}^{+}$and $\mathrm{CFA} / \mathrm{I}^{-}$strains selected by the author (strains used in Wadström et al., 1979) (Fig. 2 , lanes 5 and 6 ). Each extract from the $\mathrm{CFA} / \mathrm{I}^{+}$member of the paired strains showed a major polypeptide band of $13.8 \mathrm{kDal}$ which was lacking in the polypeptide band profiles of extracts of the CFA/I- variants. Heat-released extracts of strain NCTC 8623, grown under conditions allowing good expression of common type fimbriae, showed no polypeptide bands corresponding to any of those designated above (Fig. 2, lane 7). It was not established whether common type fimbriae were released by heat treatment or, as would be expected, they failed to solubilize under the present experimental conditions (McMichael \& Ou, 1979).

\section{Correlation of CS antigens with polypeptide bands in SDS-PAGE}

The correlation of the serological presence of the CS1, CS2 and CS3 antigens with biotype and the presence of characteristic polypeptide bands in SDS-PAGE profiles was tested using individual strains, multiple isolates from individual patients and single colony substrains (Table 


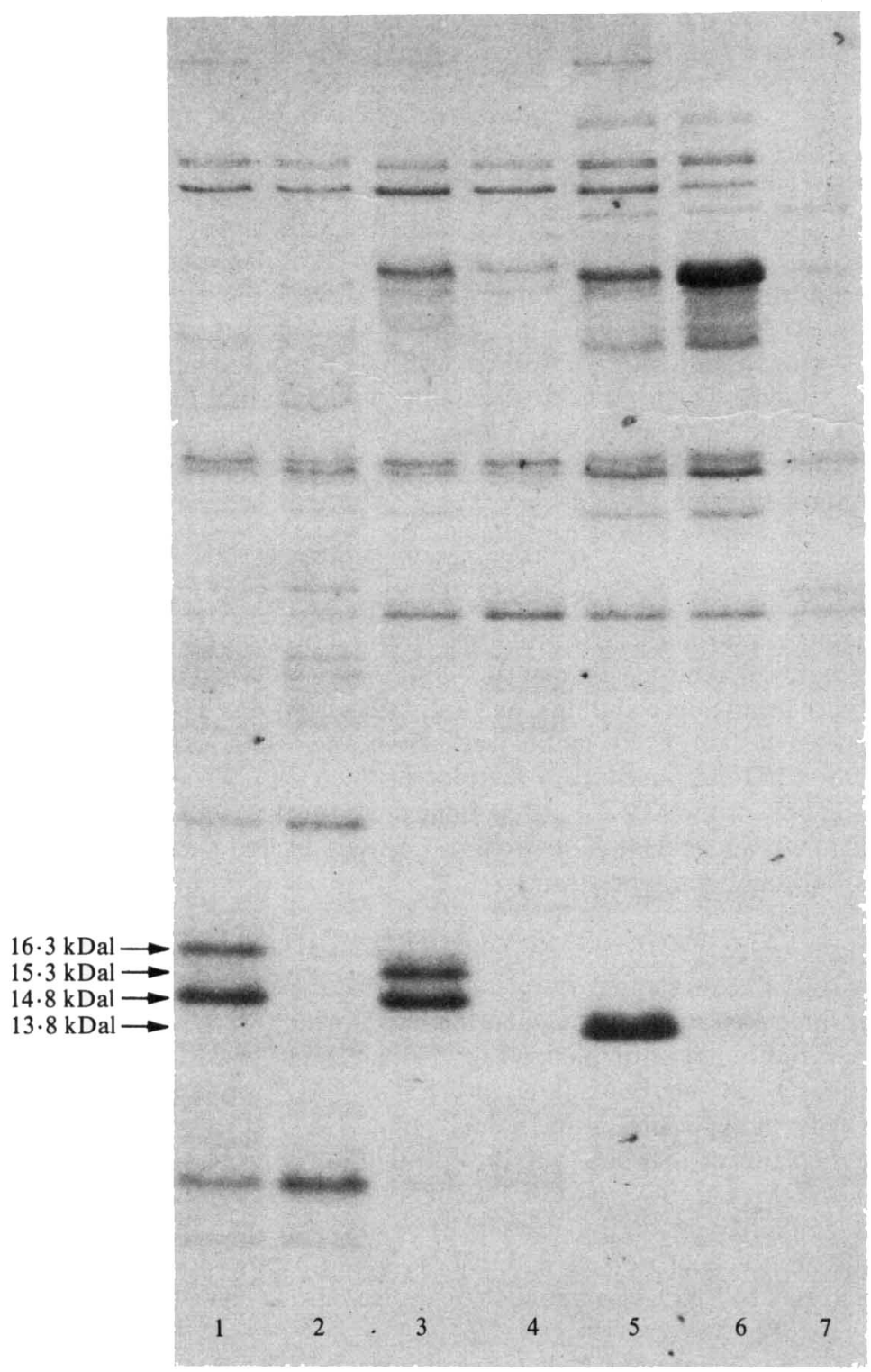

Fig. 2. SDS-PAGE of heat-released extracts of haemagglutinin-positive and haemagglutinin-negative pairs of enterotoxigenic $E$. coli. Lane 1, strain C922a-1, $\mathrm{MRHA}_{\text {bov }}^{+} \mathrm{CS}^{+} \mathrm{CS}^{+}$; lane 2, strain $\mathrm{C922a-2,}$ MRHA bov $\mathrm{CS}^{-}{ }^{-} \mathrm{CS} 2^{-}$; lane 3, strain B303dEt, $\mathrm{MRHA}_{\text {bov }}^{+} \mathrm{CS}_{2}{ }^{+} \mathrm{CS}_{3}{ }^{+}$; lane 4, strain B303d-5, MRHA bov $_{\text {bS2- } \text { CS3}^{-} \text {; lane 5, strain H-10407, MRHA human }}^{+} \mathrm{CFA}^{+} \mathrm{I}^{+}$, lane 6, strain H-10407-P, MRHA $_{\text {human }}^{-}$CFA/I ${ }^{-}$: lane 7 , strain NCTC 8623, broth-grown cells expressing type 1 fimbriae,

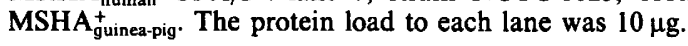

3). Twelve MRHA bov strains of biotype $A$ and seven additional multiple isolates from three patients were each agglutinated by anti-CS1 serum, possessed the CS1 and CS3 antigens, and revealed the $16.3 \mathrm{kDal}$ and $14.8 \mathrm{kDal}$ components in SDS-PAGE. Using four MRHA bov $^{-}$ substrains, loss of CS1 and CS3 serologically was accompanied by the absence of these polypeptide bands in SDS-PAGE.

In the case of strains of biotypes $\mathrm{B}, \mathrm{C}$, and $\mathrm{F}$, six $\mathrm{MRHA}_{\mathrm{bov}}^{+}$strains and a single colony substrain were agglutinated by anti-CS2 serum, possessed the CS2 and CS 3 antigens and showed 
Table 3. Biotype, agglutinability, immunodiffusion and SDS-PAGE data relating to $M R H A_{\mathrm{bov}}^{+}$ enterotoxigenic $E$. coli of serotype $O 6: K 15: H 16$ or $H-, M R H A_{\text {bov }}$ variants and other $E$. coli

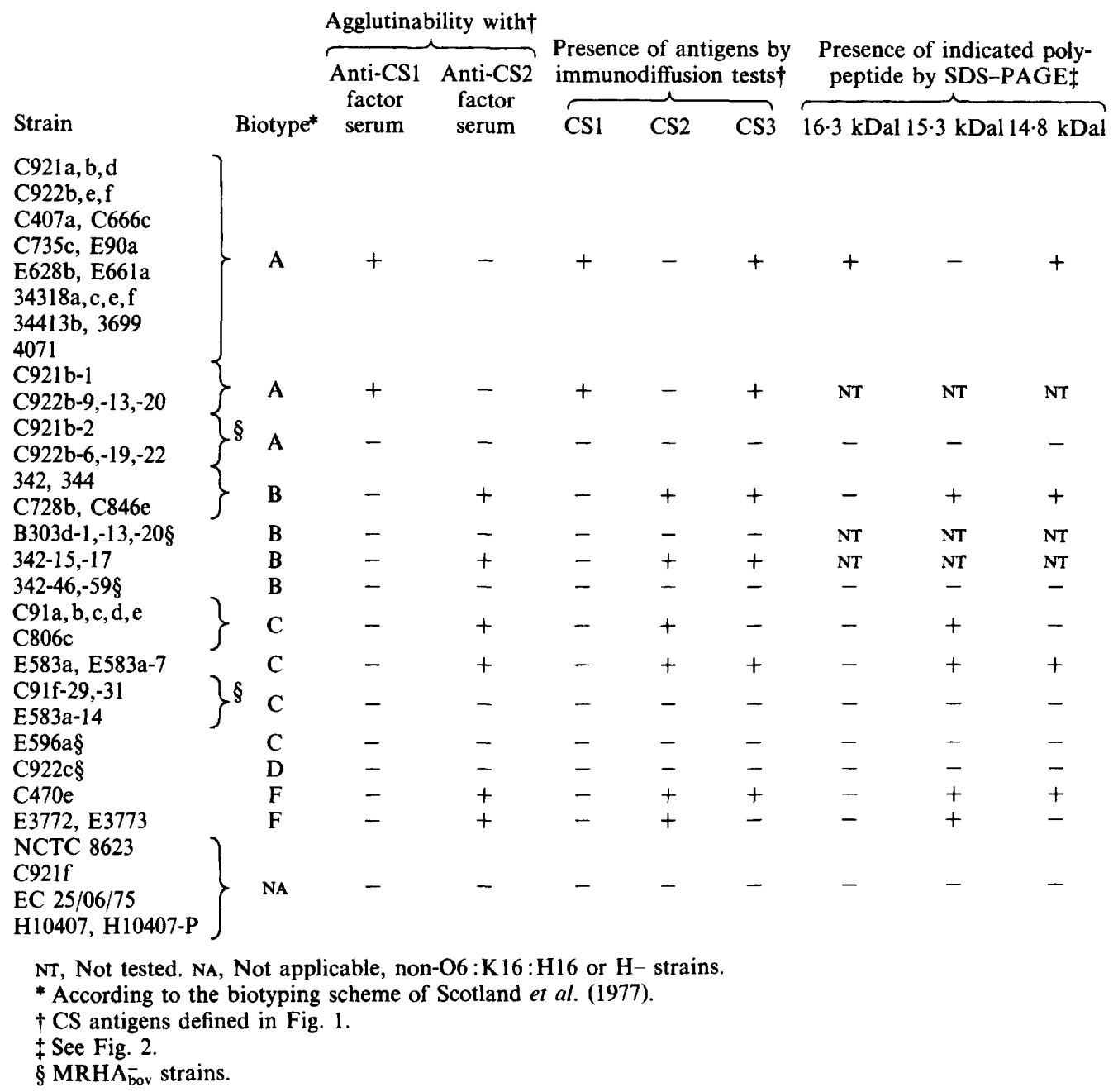

the presence of the 15.3 and $14.8 \mathrm{kDal}$ polypeptide bands in extracts. In contrast, eight MRHA $_{\text {bov }}^{+}$isolates from three patients which were agglutinated by anti-CS2 serum demonstrated only the CS2 antigen and the $15 \cdot 3 \mathrm{kDal}$ polypeptide band in SDS-PAGE profiles of extracts. Five MRHA $_{\text {bov }}^{-}$single colony substrains of these biotypes exhibited concomitant loss of agglutinability, CS2 (and CS3) antigen(s) and the $15.3 \mathrm{kDal}$ (and $14.8 \mathrm{kDal}$ ) polypeptide band(s). In addition, two MRHA bov $^{-}$enterotoxigenic strains of biotypes $\mathrm{C}$ and $\mathrm{D}$ and one enterotoxigenic strain of serotype $06: \mathrm{K} 13$ and one non-enterotoxigenic strain of serotype $\mathrm{O} 6: \mathrm{K} 2: \mathrm{H} 1$ were serologically negative for $\mathrm{CS} 1, \mathrm{CS} 2$ and $\mathrm{CS} 3$ and lacked the characteristic polypeptide bands in SDS-PAGE.

Thus, in each case, the immunologically identified CS1, CS2 and CS3 antigens correlated with the $16 \cdot 3,15 \cdot 3$ and $14 \cdot 8 \mathrm{kDal}$ polypeptide bands, respectively.

\section{Haemagglutination profiles}

In view of the apparent association of CS1 antigen with biotype A and of CS2 antigen with biotypes B, C and F, the MRHA profiles of these enterotoxigenic $E$. coli were examined to 
determine whether or not differences might exist between the haemagglutinins on the different biotypes. Eleven species of erythrocyte other than bovine were tested.

As previously described (Evans \& Evans, 1978; Smyth et al., 1979; Wadström et al., 1979), all MRHA $_{\text {bov }}^{+}$strains failed to agglutinate human erythrocytes. Eight other species of erythrocyte (cat, dog, guinea-pig, horse, mouse, pig, rabbit and sheep) were likewise not agglutinated in the presence of mannose. Chicken erythrocytes from 6 week old broiler fowl were agglutinated (Evans, D. J. et al., 1979) irrespective of the biotype. Biotype A strains failed to agglutinate hen erythrocytes (White Leghorn breed) in the presence of mannose, whereas the strains of biotypes $\mathrm{B}, \mathrm{C}$ and $\mathrm{F}$ caused rapid agglutination of this blood type. The latter strains tended to agglutinate hen erythrocytes more rapidly and readily than bovine erythrocytes. Strain B34212j did not agglutinate any of these test bloods.

No strain grown on CFA agar medium haemagglutinated guinea-pig erythrocytes in the absence of mannose. Only strains C91a-f, C806c and C922c, when grown and passaged in TSB without shaking, demonstrated MSHA of guinea-pig and chicken or hen erythrocytes, indicating the presence of type 1 fimbriae (Nowotarska \& Mulczyk, 1977; Sweeney \& Freer, 1979; Duguid \& Old, 1980).

None of the MRHA $_{b o v}$ variants grown on CFA agar agglutinated any of the test bloods in the presence of mannose. However, TSB-grown cells of the MRHA ${ }_{\text {bov }}$ variants of strain C91f gave $\mathrm{MSHA}_{\text {guinea-pig }}$ and $\mathrm{MSHA}_{\text {hen }}$, like their parent strain.

\section{Loss of enterotoxigenicity in relation to loss of antigens CS1, CS2 and CS3}

Of the $16 \mathrm{MRHA}_{\mathrm{bov}}^{-}$variants studied, 13 lost the ability to produce both LT and ST (Table 1). The remaining three retained LT production. Thus, loss of ST with or without concomitant loss of LT production accompanied loss of the $\mathrm{MRHA}_{\text {bov }}$ property and of the CS1, CS2 and CS3 antigens.

\section{DISCUSSION}

Enterotoxigenic $E$. coli of serogroups $\mathrm{O} 6$ and $\mathrm{O} 8$ of human origin have been previously shown

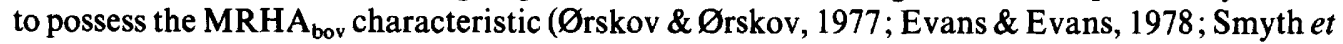
al., 1979). Moreover, this haemagglutinating ability has been taken to be indicative of or synonymous with the presence of CFA/II, a fimbriate adhesin on the cell surface of such strains (Evans \& Evans, 1978; Bäck et al., 1980a, b; Levine et al., 1980). Although there are differences of opinion at present as to the number of different biotypes within enterotoxigenic $E$. coli of serotype O6:K15:H16 or H- (Ørskov \& Ørskov, 1977; Scotland et al., 1977; Merson et al., 1979), five biotypes were recorded herein, only four of these being associated with MRHA bov $^{+}$ strains. The strain C922c of biotype D was $\mathrm{MRHA}_{\mathrm{bov}}^{-}$. The presence of CS1 antigen or of CS2 antigen in these bacteria correlated with fermentation of rhamnose, namely, biotype A strains possessed CS1 antigen and were rhamnose-negative, whereas rhamnose-positive strains (biotypes B, C and F) possessed the CS2 antigen. Moreover, antisera specific for CS1 and CS2 only neutralized the MRHA $_{\text {bov }}$ reactions of rhamnose-negative and rhamnose-positive strains, respectively. Rhamnose-positive and rhamnose-negative strains were also found to differ with respect to their abilities to agglutinate hen erythrocytes. Thus, these closely related enterotoxigenic $E$. coli of identical $\mathrm{O}: \mathrm{K}: \mathrm{H}$ serotype may posssess one or other of two antigenically distinct mannose-resistant haemagglutinins with slightly differing biological properties.

It is not possible to directly identify CS1, CS2 or CS3 antigen with the common antigen detected by Evans \& Evans (1978) in extracts of enterotoxigenic E. coli of serogroups O6 and O8 by using immunodiffusion tests without access to their prototype strain PB-176 and their reference CFA/II antiserum sensu stricto. However, strain PB-176 is of biotype A, i.e. rhamnosenegative (F. \& I. Ørskov, WHO Collaborative Centre for Research and Reference on Escherichia coli, Copenhagen, Denmark, personal communication). Moreover, strains C922a-1 and C922a-2, the prototype biotype A strains herein of MRHA $_{b o v}^{+}$and $\mathrm{MRHA}_{\mathrm{bov}}^{-}$character, have been typed as CFA $/ \mathrm{II}^{+}$and $\mathrm{CFA} / \mathrm{II}^{-}$, respectively (tests kindly performed by $\mathrm{D}$. G. and $\mathrm{D}$. 
J. Evans, Jr, University of Texas Medical School at Houston, Houston, Tex., U.S.A.). Thus, the likely candidate is CSI or CS3. If all the enterotoxigenic $06: \mathrm{H} 16$ strains examined by Evans \& Evans (1978) were of biotype A, then the common immunoprecipitate might have been due to either antigen. If they were not all of biotype A, CSI would seem improbable. Moreover, the $\mathrm{CS} 3$ antigen was the only antigen common to most of the enterotoxigenic $\mathrm{MRHA}_{\text {bov }}^{+}$, Oserogroup 6 strains in the present investigation and was also found on an enterotoxigenic $\mathrm{O}$ serogroup 8 series of isolates, which is consistent with the description of Evans \& Evans (1978) for CFA/II antigen detected in surface extracts of their strains. Finally, although the property of MRHA $_{\text {bov }}$ correlated with tissue adhesiveness and the presence of fimbriae on PB-176, Evans \& Evans (1978) did not establish that the precipitating antibodies inhibited haemagglutination or tissue adhesiveness or bound to the fimbriae, i.e. that their antigen detected by immunodiffusion was synonymous with the haemagglutinin, the tissue adhesin or fimbrial in nature.

The enterotoxigenic $\mathrm{MRHA}_{\text {bov }}^{+}$strain of serotype O6:H16, i.e. E1392/75, used by Cravioto $e t$ al. (1979a) to raise a putative anti-CFA/II antiserum was also of biotype A (Scotland et al., 1977). Moreover, the immunoprecipitate obtained with surface extracts of their strain was stated to show identity with that obtained with extracts of PB-176 using antiserum absorbed in an identical manner to that used both herein and by Evans \& Evans (1978). Whether these precipitating antibodies had HI activity was not investigated. Based on the present findings, Cravioto et al. (1979a) may have been observing CS1 or CS3 antigen in immunodiffusion.

One other group has reported on the occurrence of adhesins on enterotoxigenic $E$. coli of Oserogroup 6 (Deneke et al., 1980, 1981; Thorne et al., 1979). Interestingly their strains B2C and TD219c1 (both of serotype O6: H16) possessed serologically distinct fimbriae corresponding to those found on prototype strains M9800-5 and D563 of unknown serotype (Deneke et al., 1980, 1981). A third strain of serotype O6:H16 (TD462cl) reacted with the antisera prepared to fimbriae from both M9800-5 and D563. These authors' observations are complicated by their apparent requirement to cross-link fimbriae with the bifunctional reagent $N, N^{\prime}-p$ phenylenedimaleimide in order to obtain immunoprecipitation in immunodiffusion tests. Furthermore, these authors did not report on the ability of their antisera to inhibit haemagglutination nor on the biotypes of their strains. Thus, unfortunately, it is not possible to directly compare their findings with those presented here.

What are the natures of the CS1, CS2 and CS3 antigens? Antigens CS1, CS2 and CS3 were each associated with characteristic polypeptide bands in SDS-PAGE which were readily distinguishable from minor bands, probably contributed by sloughed off envelope material during preparation of extracts, by the comparative use of extracts of MRHA bov $^{-}$variants and of strains characterized herein as possessing only one of these antigens (see Table 3). Moreover, CFA agar grown cells of $\mathrm{MRHA}_{\text {bov }}^{+}$bacteria of serotype $\mathrm{O6}: \mathrm{K} 15: \mathrm{H} 16$ or $\mathrm{H}$ - are heavily fimbriate, whereas their MRHA bov variants are not (J. H. Freer, A. Ellis \& C. J. Smyth, unpublished results). Recently, Jann et al. (1981) examined fimbriae from $E$. coli of different origin, including strain 20174 of serotype $\mathrm{O} 6: \mathrm{H}-$ which was stated to be $\mathrm{CFA} / \mathrm{II}^{+}$on the basis of being MRHA ${ }_{\text {bov }}^{+}$. This strain is of biotype B, rhamnose-positive (C. J. Smyth, unpublished data). Using purified preparations of fimbriae of strain 20174, two distinct polypeptide bands of unstated molecular weight were obtained with SDS-PAGE (Jann et al., 1981). Deneke et al. (1980) also reported a similar finding with a preparation of fimbriae from $E$. coli. Heat extraction of bacterial suspensions as used herein has been demonstrated to yield preparations of the fimbrial adhesins CFA/I (Freer et al., 1978) and the F7 antigen (Ørskov et al., 1980). Thus, although the present apparent molecular weights of observed polypeptide bands with SDSPAGE can not be readily compared with data from the studies of Jann et al. (1981) and of Deneke et al. (1980), the molecular weights of the polypeptide bands associated with the presence of CS1, CS2 and CS3 in extracts of $\mathrm{MRHA}_{\text {bov }}^{+}$strains are not inconsistent with reported molecular weights for fimbrial subunit proteins (Brinton, 1978; Deneke et al., 1980; Wevers et al., 1980; Jann et al., 1981). One interpretation of the SDS-PAGE data has been that two different subunits may exist in a single fimbrial structure (Deneke et al., 1980; Jann et al., 1981). However, the serological data of the present report would not be consistent with this view in the case of the CS antigens as neither heat-release nor shearing is likely to yield fimbrial subunits. In 
contrast, that more than one type of fimbria or adhesin may be present on $E$. coli is not without precedent (e.g. Morris et al., 1980; Ørskov et al., 1980).

Although the CS3 antigen appears to be non-haemagglutinating, this does not exclude the possibility that it could have adhesive significance in vivo. For example, the 987P antigen found on certain porcine enterotoxigenic $E$. coli lacks haemagglutinating activity (Isaacson \& Richter, 1981). Tests with ten of the erythrocyte species used herein and the prototype strain 987 have also proved negative in this laboratory (C. J. Smyth, unpublished data). Moreover, strain B34212 (CS3 only) has been shown to adhere to human intestinal epithelial cells (Wadström $e t$ al., 1980). However, just as all fimbriae are not haemagglutinating (Duguid \& Old, 1980; Isaacson \& Richter, 1981), it is also true that not all fimbriae are adhesive and that not all adhesins are fimbrial (Duguid \& Old, 1980). Nonetheless, CS3 antigen neither appears to be an artefact of preparation nor a product of partial proteolysis of CS1 and CS2 antigens.

In summary, in contrast to enterotoxigenic $E$. coli bearing the haemagglutinin CFA/I, strains producing so-called CFA/II or putatively identified as $\mathrm{CFA} / \mathrm{II}^{+}$on the basis of the possession of the MRHA $_{\text {bov }}$ property, appear to produce more than one type of adhesin. There is a need to resolve the comparative descriptions of adhesins on enterotoxigenic $E$. coli of serogroup O6 of human origin before more extensive genetic analysis of such strains is undertaken. It is also to be recommended that future investigators report the biotype of strains according to the scheme of Scotland et al. (1977) but especially the results of the differential rhamnose test to enable better comparison of findings between research groups.

I thank E. Bäck, G. Stintzing and R. Möllby for providing strains, for their interest and encouragement throughout these investigations and for their moral support of publication of these findings; I also wish to thank the following: M. Gurwith for providing biotype B strains; F. \& I. Ørskov for serotyping some strains, for antiserum and biotype information, and their interest in these studies; B. Kaijser, who originally $O: K$ serotyped almost all of the strains used in this study; S. Scotland for information about biotyping of O6:H16 strains; D. G. and D. J. Evans for CFA/II analysis of a pair of prototype strains and their encouragement at early stages in this work; L.-G. Josefsson for performing the SDS-PAGE analyses; to E. Olsson and G. Sigstam for enterotoxin tests and $\mathrm{K}$. Zimmerman for painstaking excellent technical assistance.

\section{REFERENCES}

Bäck, E., Svennerholm, A.-M., Holmgren, J. \& MöllbY, R. (1979). Evaluation of a ganglioside immunosorbent assay for detection of Escherichia coli heat-labile enterotoxin. Journal of Clinical Microbiology 10, 791-795.

BÄCK, E., MÖLLBY, R. \& KAUSER, B. (1980a). Relative importance, seasonal variation, $\mathrm{O}$ - and $\mathrm{K}$-antigens of enterotoxigenic Escherichia coli: a three-and-ahalf year review in Sweden. Journal of Infection 2, 302-315.

BÄCK, E., Möllby, R., Kaijser, B., Stintzing, G., WADSTRÖM, T. \& HABTE, D. (1980 b). Enterotoxigenic Escherichia coli and other gram-negative bacteria of infantile diarrhea: surface antigens, hemagglutinins, colonization factor antigen, and loss of enterotoxigenicity. Journal of Infectious Diseases 142, 318-327.

Brinton, C. C., JR (1978). The piliation phase syndrome and the uses of purified pili in disease control. In XIIIth US-Japan Conference on Cholera, United States Department of Health, Education and Welfare Publication No. NIH 78-1590, pp. 34-60. Edited by C. Miller. Bethesda, Md., U.S.A.: National Institutes of Health.

Brunton, J., Hinde, D., Langston, C., Gross, R., Rowe, B. \& GURWITH, M. (1980). Enterotoxigenic
Escherichia coli in central Canada. Journal of Clinical Microbiology 11, 343-348.

Cravioto, A., Gross, R. J., Scotland, S. M. \& Rowe, B. $(1979 a)$. An adhesive factor found in strains of Escherichia coli belonging to the traditional infantile enteropathogenic serotypes. Current Microbiology 3, 95-99.

Cravioto, A., Gross, R. J., Scotland, S. M. \& Rowe, B. $(1979 b)$. Mannose-resistant haemagglutination of human erythrocytes by strains of Escherichia coli from extraintestinal sources: lack of correlation with colonisation factor antigen (CFA/1). FEMS Microbiology Letters 6, 41-44.

Deneke, C. F., Thorne, G. M. \& Gorbach, S. L. (1980). Adhesive pili for enterotoxigenic Escherichia coli pathogenic for humans. In XVth US-Japan Conference on Cholera, United States Department of Health, Education and Welfare Public Health Service Publication No. NIH 80-2003, pp. 61-83. Washington, D.C.: DHEW.

Deneke, C. F., Thorne, G. M. \& Gorbach, S. L. (1981). Serotypes of attachment pili of enterotoxigenic Escherichia coli isolated from humans. Infection and Immunity 32, 1254-1260.

Duguid, J. P. \& OLD, D. C. (1980). Adhesive properties in Enterobacteriaceae. In Bacterial Ad- 
herence, Receptors and Recognition Series B, vol. 6, pp. 185-217. Edited by E. H. Beachey. London: Chapman \& Hall.

EDWARDS, P. R. \& EWING, W. H. (1972). Identification of Enterobacteriaceae, 3rd edn. Minneapolis: Burgess Publishing Co.

Evans, D. G. \& Evans, D. J., JR (1978). New surfaceassociated heat-labile colonization factor antigen (CFA/II) produced by enterotoxigenic Escherichia coli of serogroups $\mathrm{O} 6$ and $\mathrm{O8}$. Infection and Immunity 21, 638-647.

Evans, D. G., Silver, R. P., Evans, D. J., JR, Chase, D. G., \& GoRBACH, S. L. (1975). Plasmid-controlled colonization factor associated with virulence in Escherichia coli enterotoxigenic for humans. Infection and Immunity 12, 656-667.

Evans, D. G., Evans, D. J., JR \& TJoA, W. (1977). Hemagglutination of human group A erythrocytes by enterotoxigenic Escherichia coli isolated from adults with diarrhea: correlation with colonization factor. Infection and Immunity 18, 330-337.

Evans, D. G., Evans, D. J., JR, TJoA, W. S. \& DuPoNT, H. L. (1978). Detection and characterization of colonization factor of enterotoxigenic Escherichia coli isolated from adults with diarrhea. Infection and Immunity 19, 727-736.

Evans, D. G., Evans, D. J., JR, Clegg, S. \& Pauley, J. A. (1979). Purification and characterization of the CFA/I antigen of Escherichia coli. Infection and Immunity 25, 738-748.

Evans, D. J., JR, Evans, D. G. \& DuPont, H. L. (1979). Hemagglutination patterns of enterotoxigenic and enteropathogenic Escherichia coli determined with human, bovine, chicken, and guinea pig erythrocytes in the presence and absence of mannose. Infection and Immunity 23, 336-346.

Fairbanks, G., Steck, T. L. \& Wallach, D. F. H. (1971). Electrophoretic analysis of the major polypeptides of the human erythrocyte membrane Biochemistry 10, 2606-2617.

Freer, J. H., Ellis, A., WADSTRöm, T. \& SMYth, C. J. (1978). Occurrence of fimbriae among enterotoxigenic intestinal bacteria isolated from cases of infantile diarrhoea. FEMS Microbiology Letters 3, 277-281.

Giannella, R. A. (1976). Suckling mouse model for detection of heat-stable Escherichia coli enterotoxin: characteristics of the model. Infection and Immunity 14, 95-99.

Gross, R. J., Cravioto, A., Scotland, S. M., ChEASTY, T. \& Rowe, B. (1978). The occurrence of colonisation factor (CF) in enterotoxigenic Escherichia coli. FEMS Microbiology Letters 3, 231-233.

Guerrant, R. L., Brunton, L. L., Schnattman, T. C., Rebhun, L. I. \& Gilman, A. G. (1974). Cyclic adenosine monophosphate and alteration of Chinese hamster ovary cell morphology: a rapid, sensitive, in vitro assay for the enterotoxins of Vibrio cholerae and Escherichia coli. Infection and Immunity 10, 320-327.

HARBOE, N. \& INGILD, A. (1973). Immunization, isolation of immunoglobulins, estimation of antibody titre. In A Manual of Quantitative Immunoelectrophoresis, pp. 161-164. Edited by N. H Axelsen, J. Kroll \& B. Weeke. Oslo: Universitetsforlaget.

ISAACSON, R. E. \& RICHTER, P. (1981). Escherichia coli
987P pilus: purification and partial characterization. Journal of Bacteriology 146, 784-789.

JANN, K., JANN, B. \& SCHMidT, G. (1981). SDS polyacrylamide gel electrophoresis and serological analysis of pili from Escherichia coli of different pathogenic origin. FEMS Microbiology Letters 11, 21-25.

Kudoh, Y., Matsushita, S., Yamada, S., Tsuno, M., Ohta, K., KaI, A., Sakai, S. \& OHashi, M. (1980). Travellers' diarrhea and enterotoxigenic Escherichia coli - a survey in 1977-1979 in Tokyo. In XVth USJapan Conference on Cholera, United States Department of Health, Education, and Welfare Public Health Service Publication No. NIH 80-2003, pp. 225-236. Washington, D.C.: DHEW.

LAEMMLI, U. K. (1971). Cleavage of structural proteins during assembly of the head of bacteriophage T4. Nature, London 227, 680-685.

LAZDUNSKI, A., MURGier, M. \& LAZdunski, C. (1975). Evidence for an aminopeptidase localised near the cell surface of Escherichia coli. European Journal of Biochemistry 60, 349-355.

LeVine, M. M., Rennels, M. B., DAya, V. \& Hughes, T. P. (1980). Hemagglutination and colonization factors in enterotoxigenic and enteropathogenic Escherichia coli that cause diarrhea. Journal of Infectious Diseases 141, 733-737.

MCMichael, J. C. \& OU, J. T. (1979). Structure of common pili from Escherichia coli. Journal of Bacteriology 138, 969-975.

MERSON, M. H., ØRSKOV, F., ØrsKov, I., SACK, R. B., HuQ, I. \& KOSTER, F. T. (1979). Relationship between enterotoxin production and serotype in enterotoxigenic Escherichia coli. Infection and Immunity 23, 325-329.

Morris, J. A., Stevens, A. E. \& SoJKA, W. J. (1977). Preliminary characterization of cell-free K99 antigen isolated from Escherichia coli B41. Journal of General Microbiology 99, 353-357.

Morris, J. A., THORNs, C. J. \& SOJKA, W. J. (1980). Evidence for two adhesive antigens on the K99 reference strain Escherichia coli B41. Journal of General Microbiology 118, 107-113.

Nowotarska, M. \& Mulczyk, M. (1977). Serologic relationship of fimbriae among Enterobacteriaceae. Archivum Immunologiae et Therapiae Experimentalis 25, 7-16.

OLSSON, E. \& SöDERLIND, O. (1980). Comparison of different assays for definition of heat-stable enterotoxigenicity of Escherichia coli porcine strains. Journal of Clinical Microbiology 11, 6-15.

ØrSKov, I. \& ØRSKOV, F. (1977). Special O:K:H serotypes among enterotoxigenic $E$. coli strains from diarrhea in adults and children. Occurrence of the $\mathrm{CF}$ (colonization factor) antigen and of hemagglutinating abilities. Medical Microbiology and Immunology 163, 99-110.

ØRSKOV, I., ØRSKOV, F. \& BirCH-ANDERSEN, A. (1980). Comparison of Escherichia coli fimbrial antigen F7 with type 1 fimbriae. Infection and Immunity 27, 657666.

Paucaud, M., Sibilli, L. \& Le Bras, G. (1976). Protease 1 from Escherichia coli. Some physicochemical properties and substrate specificity. European Journal of Biochemistry 69, 141-151.

Scotland, S. M., Gross, R. J. \& Rowe, B. (1977). 
Serotype-related enterotoxigenicity in Escherichia coli O6. H16 and O148. H28. Journal of Hygiene 79, 395-403.

SMYTH, C. J. (1980). Serological heterogeneity and biotype specificity of mannose-resistant haemagglutinins on enterotoxigenic Escherichia coli of serotype $06: \mathrm{K} 15: \mathrm{H} 16$ or $\mathrm{H}-$ isolated from travellers' and infantile diarrhea. Federation of European Microbiological Societies Symposium on Microbial Envelopes, May 26-30, 1980, Saimaanranta, Finland. Abstract No. 109

SMYTH, C. J., KaIJSER, B., BÄCK, E., FARIS, A., Möllby, R., Söderlind, O., Stintzing, G., WADSTRÖM, T. \& HABTE, D. (1979). Occurrence of adhesins causing mannose-resistant haemagglutination of bovine erythrocytes in enterotoxigenic Escherichia coli. FEMS Microbiology Letters 5, 8590.

SöDERLIND, O. \& MöllbY, R. (1978). Studies on Escherichia coli in pigs. V. Determination of enterotoxicity and frequency of $\mathrm{O}$ groups and $\mathrm{K} 88$ antigen in strains from 200 piglets with neonatal diarrhoea. Zentralblatt für Veterinärmedizin B25, 719-728.

Stintzing, G., Bäck, E., Tufvesson, B., Johnsson, T., WAdströM, T. \& HABTE, D. (1981). Seasonal fluctuations in the occurrence of enterotoxigenic bacteria and rotavirus in paediatric diarrhoea in Addis Ababa. Bulletin of the World Health Organization 59, 67-73.

Stintzing, G., Möllby, R. \& HabTe, D. (1982). Enterotoxigenic Escherichia coli and other enteropathogens in paediatric diarrhoea in Addis Ababa. Acta paediatrica scandinavica 71, 279-286.

STIRM, S., ØRSKOV, I., ØRSKOV, F. \& MANSA, B. (1967). Episome-carried surface antigen K88 of Escherichia coli. II. Isolation and chemical analysis. Journal of Bacteriology 93, 731-739.

SWEENEY, G. \& FreER, J. H. (1979). Location of binding sites on common type 1 fimbriae from
Escherichia coli. Journal of General Microbiology 112, 321-328.

Thorne, G. M., Deneke, C. F. \& Gorbach, S. L. (1979). Hemagglutination and adhesiveness of toxigenic Escherichia coli isolated from humans. Infection and Immunity 23, 690-699.

W ADström, T., SMYTh, C. J., FARIS, A., Jonsson, P. \& FreER, J. H. (1979). Hydrophobic adsorptive and hemagglutinating properties of enterotoxigenic Escherichia coli with different colonizing factors: K88 antigen, K99 antigen, colonization factor antigens and adherence factor. In Proceedings of the Second International Symposium on Neonatal Diarrhea, pp. 29-55. Edited by S. Acres. Saskatoon, Canada: Veterinary Infectious Diseases Organization (VIDO).

Wadström, T., Faris, A., LuUngh, $\AA$. \& Habte, D. (1980a). Attachment of enterotoxigenic Escherichia coli with CFA/I and CFA/II to human epithelial cells. In XVth US-Japan Conference on Cholera, United States Department of Health, Education and Welfare Public Health Service Publication No. NIH 80-2003, pp. 103-115. Washington, D.C.: DHEW.

Wadström, T., Faris, A., Freer, J., Habte, D. HALlBERG, D. \& LJUNGH, Å. (1980b). Hydrophobic surface properties of enterotoxigenic $E$. coli (ETEC) with different colonization factors (CFA/I, CFA/II, K88 and K99) and attachment to intestinal epithelial cells. Scandinavian Journal of Infectious Diseases, Supplement 24, 148-153.

WEEKE, B. (1973). General remarks on principles, equipment, reagents, and procedures. In $A$ Manual of Quantitative Immunoelectrophoresis, pp. 15-35. Oslo: Universitetsforlaget.

Wevers, P., Picken, R., Schmidt, G., JanN, B., JaNN, K., GoleCKI, J. R. \& KIST, M. (1980). Characterization of pili associated with Escherichia coli O18ac. Infection and Immunity 29, 685-691. 